\title{
Typhoon-Induced Magnetic Disturbances: Cases in the Western Pacific
}

\author{
Chieh-Hung Chen ${ }^{1, *}$, Chung-Ho Wang ${ }^{2}$, Li-Ching Lin ${ }^{3}$, Hsien-Hsiang Hsieh ${ }^{2,4}$, Horng-Yuan Yen ${ }^{5}$, and \\ Min-Hung Shih ${ }^{2,5}$ \\ ${ }^{1}$ Department of Earth and Environmental Sciences, National Chung Cheng University, Chiayi, Taiwan \\ ${ }^{2}$ Institute of Earth Sciences, Academia Sinica, Taipei, Taiwan \\ ${ }^{3}$ International Wave Dynamics Research Center, National Cheng Kung University, Tainan, Taiwan \\ ${ }^{4}$ Lamont-Doherty Earth Observatory, Columbia University, Palisades, USA \\ ${ }^{5}$ Department of Earth Sciences, National Central University, Chung-Li, Taiwan
}

Received 28 November 2013, revised 14 March 2014, accepted 8 May 2014

\begin{abstract}
Three typhoons occurred over the western Pacific in September 2008 and were enhanced beyond category 3 as they approached Taiwan. The geomagnetic total intensity field recorded at 2 local monitoring stations in Taiwan and 1 remote station in Japan was utilized to examine the magnetic disturbances induced by these typhoons. Analytical results show that amplitude changes in the frequency domain, which are retrieved from the total intensity data via the Fourier transform, at the monitoring and remote stations were consistent, even though magnetic storms strongly affected the magnetic field. However, obvious discrepancies were repeatedly found in the amplitudes in the frequency band between $0.0025-0.007 \mathrm{~Hz}$, when typhoons of category $>3$ were the closest to the monitoring stations. The frequency band is different from the induction fields from either oceanic storm waves or swells, and is consistent with that of magnetic pulsations triggered by acoustic waves from upward air motion during typhoons.
\end{abstract}

Key words: Typhoon, Magnetic disturbance, Acoustic wave

Citation: Chen, C. H., C. H. Wang, L. C. Lin, H. H. Hsieh, H. Y. Yen, and M. H. Shih, 2014: Typhoon-induced magnetic disturbances: Cases in the Western Pacific. Terr. Atmos. Ocean. Sci., 25, 647-653, doi: 10.3319/TAO.2014.05.08.01(AA)

\section{INTRODUCTION}

Sea water is a fairly good electrical conductor. When sea water is moved by oceanic currents and ocean waves, electrical fields, currents and secondary magnetic fields are induced impacting the Earth's magnetic field (Lilley et al. 2001; Maus and Kuvshinov 2004). Fraser (1966) once mounted a magnetometer on the sea bed and found amplitudes of induced magnetic fields, which were enhanced at a particular frequency band (about $0.1-0.2 \mathrm{~Hz}$ ) agreeing with the frequency characteristics of ocean waves. The agreement between the experimental results and theoretical predictions in either amplitude or frequency suggests that the induction field is caused by the electric current induced from the motion of ocean waves through the Earth's magnetic field. Thus, ocean waves and excited secondary magnetic fields generally yield similar frequency characteristics

\footnotetext{
* Corresponding author

E-mail:nononochchen@gmail.com
}

of approximately $0.1-0.2 \mathrm{~Hz}$ and have attracted considerable attention for a long time (Weaver 1965; Fraser 1966; Lilley et al. 1993, 2004).

Wind is one of the significant driving forces of ocean waves and is caused by the atmospheric pressure gradient due to differences in air temperature. When the heated moisture is persistently evaporated and propagates upward over the warm ocean surface, a large whirl with intense wind is created, and in many cases, further develops to form tropical storms. Once the wind speed exceeds $17.2 \mathrm{~m} \mathrm{~s}^{-1}$ tropical storms are enhanced and form powerful typhoons (in the Pacific Ocean) or hurricanes (in the Atlantic Ocean and Caribbean Sea). Swell waves, which are one kind of gravity waves (Collard et al. 2009), are triggered by continuously intense wind, and can often be observed during the prevailing typhoon period (Munk et al. 1963). Swell waves have a narrow range of frequencies of about $0.05-0.1 \mathrm{~Hz}$ (particularly at $0.0588 \mathrm{~Hz}$ ) (Lilley et al. 2004). Once secondary magnetic fields are induced by swell waves during typhoon 
periods frequency characteristics of about $0.0588 \mathrm{~Hz}$ can be observed from magnetic data recorded at stations that are sufficiently close to be affected by the induction field.

$1-\mathrm{Hz}$ geomagnetic total intensity data recorded at 2 monitoring stations (TT and HC) in Taiwan (Yen et al. 2004; Chen et al. 2009, 2013) and 1 remote station (KNY) in Japan (Fig. 1) were utilized in this study to investigate geomagnetic disturbances triggered by 3 typhoons over the western Pacific Ocean in September 2008. Geomagnetic data were transformed into the frequency domain to examine discrepancies in amplitudes at particular frequency bands between the monitoring and remote stations. The associated frequency bands were compared with data from typhoons, ocean waves and swell waves to identify possible mechanisms.

\section{METHODOLOGY}

Night time (20:00 - 4:00 local time) geomagnetic data were utilized to reduce the complex disturbances from solar activity (Wen et al. 2012). Eight-hour data were transformed into the frequency domain using a 1-hour time span via the fast Fourier transform. Eight amplitudes were obtained each day and were superimposed as the daily amplitude for either suppressing the unwanted noise or enhancing desired signals. The normalized daily amplitudes $\left[A^{\prime}(f)\right]$ were ob- tained from the daily amplitudes $[A(f)]$ as follows:

$A^{\prime}(f)=A(f) / \sum A(f)$

where $f$ is the frequency for fairly comparing data retrieved from different times and/or sites. The correlation coefficient is a common method used to quantify discrepancies between two series data. Correlation coefficients were utilized in this work to quantify discrepancies in amplitude changes within particular frequency bands between one monitoring station (i.e., either TT or HC) and the remote site (i.e., KNY) day by day. Thirty correlation coefficient values were obtained in the 30-day study period (September 2008). Variations in the time-varying correlation coefficient were compared with typhoons in the temporal domain. The corresponding frequency bands were further analysed to investigate the causal mechanisms of the magnetic disturbances.

\section{OBSERVATIONS}

Changes in the geomagnetic total intensity field recorded at 3 stations in September 2008 are shown in Fig. 2. It is clear that diurnal variations with a range of about $20 \mathrm{nT}$ were observed daily at each station, except for periods on



Fig. 1. The map of Typhoons Sinlaku, Hagupit and Jangmi as well as locations of the 3 magnetic stations. White lines denote the routes of the typhoons. Distinct sizes and colors of the solid circles lying on the white lines indicate different categories of typhoons. The red rectangles are locations of the 3 magnetic stations. 


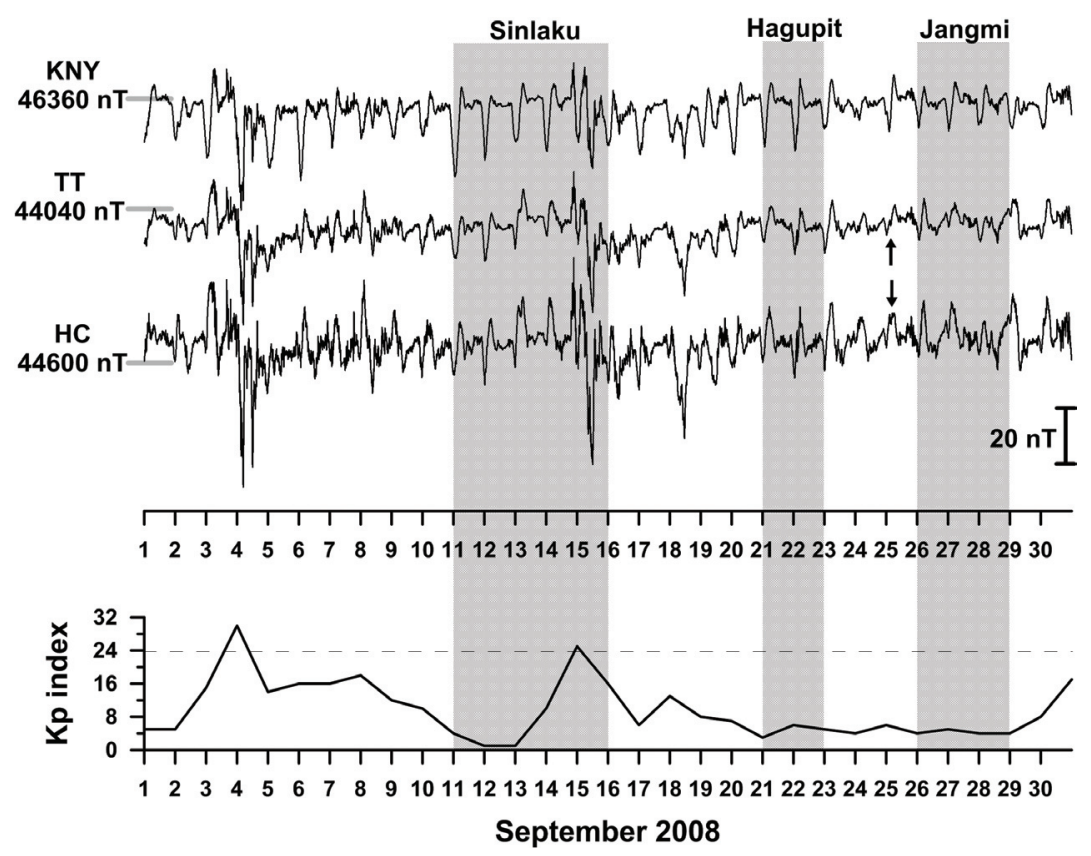

Fig. 2. Variations in geomagnetic total intensity fields at 3 magnetic stations and the Kp index in September 2008. The shadow zones indicate the impacting durations of typhoons on Taiwan. Notably, the arrows denote significant discrepancies in geomagnetic total intensity field recorded at the HC and TT stations on 25 September 2008.

the 4 and 15 September due to magnetic storms (also see the Kp index). Three typhoons (Sinlaku, Hagupit and Jangmi) occurred over the western Pacific Ocean within the month. Typhoons Sinlaku and Jangmi had similar routes in a 7-day period (10 - 16 September 2008) and a 4-day period (26 - 29 September 2008), and landed on northeastern Taiwan on 14 and 28 September 2008, repectively (Fig. 1). Both Sinlaku and Jangmi remained within category 4 as super typhoons throughout September 11 and 27, and quickly diminished on 13 and 27 September 2008, respectively, due to their storm margins touching the island of Taiwan. In contrast, Typhoon Hagupit traversed the Bashi Channel between Y'Ami Island (Philippines) and Lanyu Island (Taiwan) from 21 - 23 September 2008. Hagupit reached category 3 when it had a minimum distance from Taiwan on 23 September. Changes in the geomagentic total intensity field at the HC, TT and KNY stations were very similar on both the magnetic storm days and the typhoon-impacting days (Fig. 2). Apparently, it is very difficult to retrieve typhoon-related signals from such timeseries data. However, the monthly average amplitudes and the daily amplitudes in the frequency domain were utilized to isolate possible typhoon effects on the magnetic field.

Variations in the geomagnetic field generally result from solar activities on a worldwide scale, and have an impact on nearby observation stations on a local scale (Wen et al. 2012). It is possible to determine local impacts when data recorded by a remote station are also taken into consideration. Figure $3 \mathrm{a}$ shows that the monthly average amplitudes in September 2008 were generally smooth with an inverse relationship to frequency and consistently observed at either local monitoring or remote stations. The similarity of those average amplitudes at these 3 stations strongly suggests that solar activities dominated changes in the geomagnetic field in most periods in September 2008. Regarding the intense disturbance from the magnetic storm on 4 September, amplitudes at a frequency of $0.0035 \mathrm{~Hz}$ were obviously enhanced along with smoothly decreasing trends in the daily amplitude (Fig. 3b). These enhanced amplitudes were recurrently observed at the local monitoring and remote stations and considered to be worldwide-scale effects due to solar activities. On 13 September 2008, as Typhoon Sinlaku was approaching Tawain, the daily amplitudes at frequencies above $0.01 \mathrm{~Hz}$ (the vertical dashed line of Figs. 3c and d) between the local monitoring and remote stations were generally comparable (Fig. 3c). By contrast, a significant discrepancy was observed from the daily amplitudes at frequencies $<0.01 \mathrm{~Hz}$ between the local monitoring and remote stations, presumably due to the differences in their distances from the typhoon. The same discrepancy between the daily amplitudes at low frequencies $(<$ about $0.01 \mathrm{~Hz})$ relative to those at high frequencies $(>$ about $0.01 \mathrm{~Hz}$ ) was also observed as Typhoon Jangmi was moving toward Taiwan on 27 September 2008 (Fig. 3d).

The correlation coefficient (CC) was computed for September 2008 from the two normalized amplitudes for one local station (either HC or TT) and the remote station (KNY) to quantitatively illustrate the different changes within selected frequency bands; the variations in $\mathrm{CC}$ for the three 
distinct frequency bands are plotted in Fig. 4 as a function of time together with the $\mathrm{CC}$ between $\mathrm{TT}$ and $\mathrm{HC}$ for reference. It is clear that the $\mathrm{CC}$ values computed using the frequency band of either $0.0001-0.1$ or $0.001-0.01 \mathrm{~Hz}$ remained high $(\sim 1)$ over the study period. However, the daily amplitudes for the frequency band between 0.0025 and $0.007 \mathrm{~Hz}$ yield $\mathrm{CC}$ values that are generally high $(\sim 1)$ over the entire month, except for three obvious drops $(\mathrm{CC}<0.7$ on 13 September; $\mathrm{CC} \sim 0.85$ on 23 September; $\mathrm{CC}<0.7$ on 27 September). These three drops coincided with the times when each of the three typhoons was closest to Taiwan. Notably, tiny drops $(\sim 0.98)$ were also observed in the $\mathrm{CC}$ values for the other two frequency bands $(0.0001-0.1$ and $0.001-0.01 \mathrm{~Hz})$ on the same days, due to partial overlaps with the anomalous frequency band between $0.0025-0.007 \mathrm{~Hz}$.

\section{DISCUSSION AND CONCLUSIONS}

It is clear that an unusual drop occurred in the $\mathrm{CC}$ values for the frequency band $0.0025-0.007 \mathrm{~Hz}$ using the normalized amplitude at the $\mathrm{HC}$ and KNY stations, on 25 September 2008. To further clarify the unusual drop, the $\mathrm{CC}$ values derived from the 3 frequency bands between two monitoring stations (HC and TT) were also calculated. The
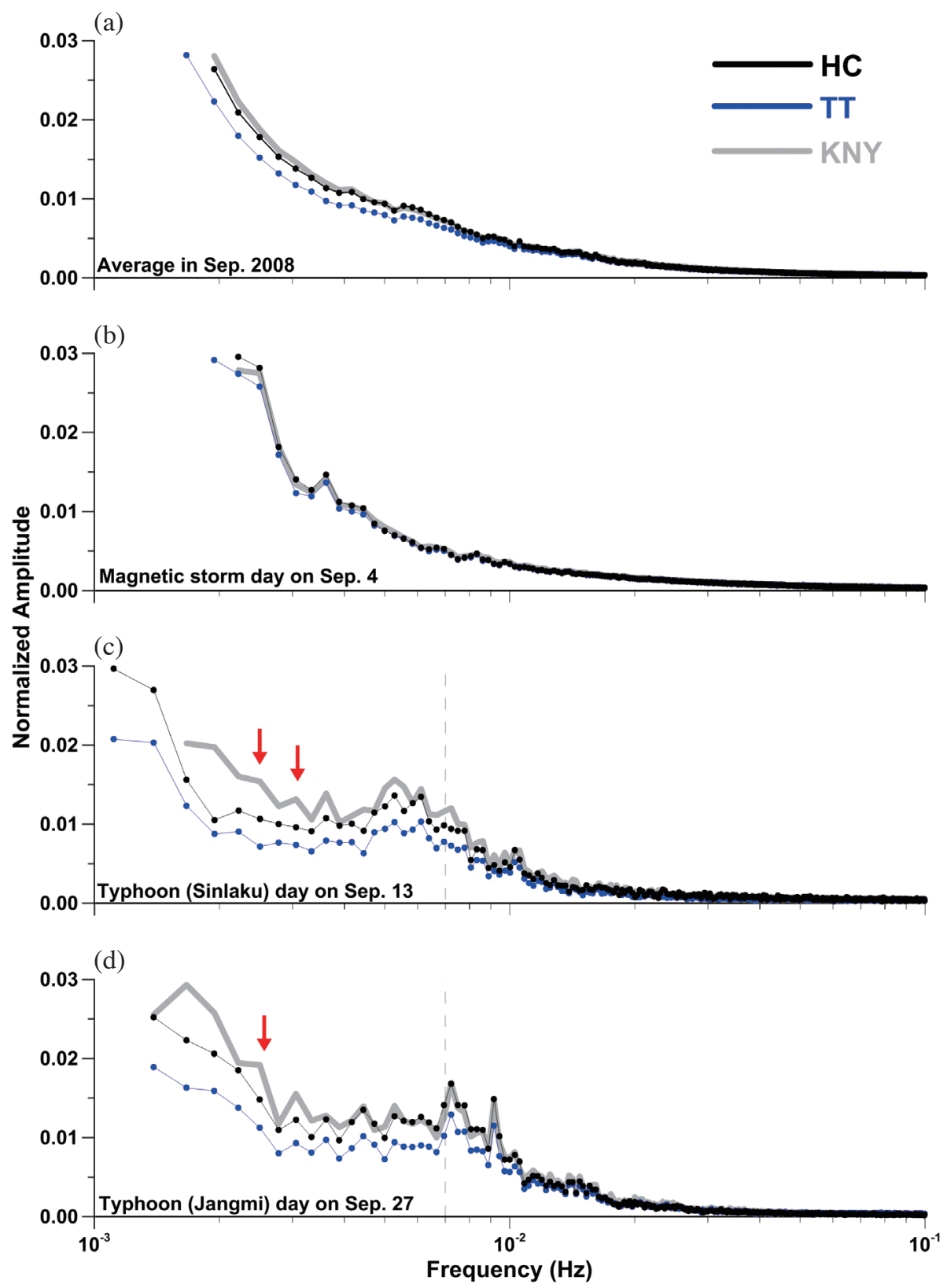

Fig. 3. The normalized amplitudes at the 3 magnetic stations. (a) in September 2008; (b) the magnetic storm day on 4 September; (c) the typhoon day on 13 September; (d) the typhoon day on 27 September. 


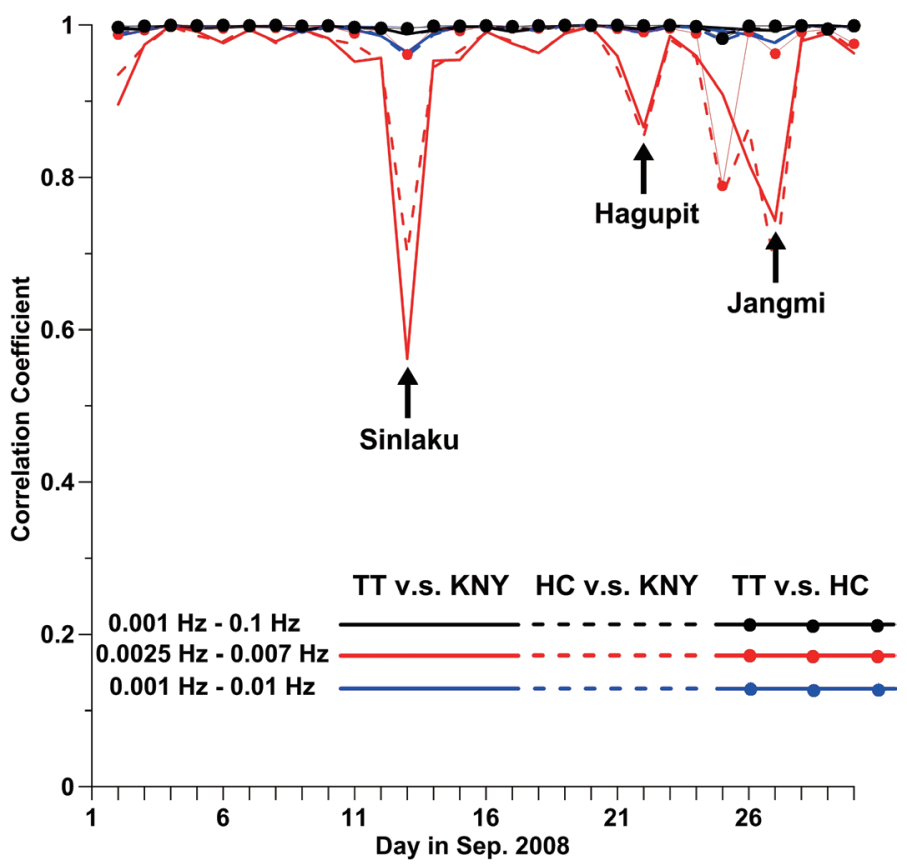

Fig. 4. Variations in the correlation coefficient calculated from normalized daily amplitudes at pairs of stations for September 2008.

$\mathrm{CC}$ values between stations $\mathrm{HC}$ and TT for the frequency band $0.0025-0.007 \mathrm{~Hz}$ also show a similar significant decrease on 25 September 2008. Cross comparisons (HC vs. $\mathrm{KNY}$ and $\mathrm{HC}$ vs. TT), show that the anomalous drops were caused by changes in amplitudes at station $\mathrm{HC}$ that were different from those at the others. Furthermore, changes in the geomagnetic total intensity field recorded at station $\mathrm{HC}$ were different from those at stations TT and KNY on 25 September 2008 (arrows in Fig. 2). Typhoons with a radius exceeding $200 \mathrm{~km}$ affected the magnetic field around station TT as well as around station HC. The disturbances recorded only at station $\mathrm{HC}$ should therefore be caused by artificial noise and/or unknown factors.

Magnetic pulsations with frequency characteristics about $0.05-0.1 \mathrm{~Hz}$ are related to the induction field directly excited by the ocean waves and/or swell waves (Weaver 1965; Fraser 1966; Lilley et al. 1993, 2004). In contrast, magnetic pulsations can also be related to transit acoustic-gravity waves from the lithosphere to the lower thermosphere (Liu et al. 2006, 2011; Occhipinti et al. 2006, 2008, 2010, 2011; Balasis and Mandea 2007; Rolland et al. 2010; Kherani et al. 2012) or a duct resonance of acoustic-gravity waves between the ground and lower thermosphere (Harkrider 1964; Francis 1973; Tahira 1995; Iyemori et al. 2005) to affect the geomagnetic field with frequency characteristics of around $0.001-0.0001 \mathrm{~Hz}$. Rolland et al. (2011) further identified frequency characteristics associated with acoustic and gravity waves from changes in the total electron content triggered by the Tohoku earthquake. The magnetic pulsations with frequency characteristics around 0.00368 and $0.0044 \mathrm{~Hz}$ are considered to result from acoustic waves (also see Nishida et al. 2000 and Occhipinti et al. 2013). In contrast, the magnetic pulsations excited by gravity waves lie in a frequency band around $0.0001 \mathrm{~Hz}$.

The anomalous frequency band $(0.0025-0.007 \mathrm{~Hz})$ identified in this study, is significantly different with the bands $0.1-0.2,0.05-0.1$, and $0.0001 \mathrm{~Hz}$. This suggests that the magnetic disturbance observed in this study was caused by neither the induction field directly excited by ocean waves and/or swell waves nor gravity waves. However, the frequency band (i.e., $0.0025-0.007 \mathrm{~Hz}$ ) is very close to that of frequency-dependent magnetic pulsations, which are caused by acoustic waves. Magnetic pulsations triggered by upward-propagating acoustic-gravity waves from the earthquake-generated Rayleigh waves and tsunamis have been widely reported in many studies (Liu et al. 2006, 2011; Occhipinti et al. 2006, 2008, 2010, 2011; Balasis and Mandea 2007; Rolland et al. 2010; Kherani et al. 2012). Typhoons can transfer a great deal of water vapor upward into the atmosphere through counterclockwise spinning in the Northern Hemisphere. The upward transportation of water vapor as vertical-motion waves can generate acoustic waves (Stopa et al. 2011) propagating upward from the lithosphere into the atmosphere, further disturbing the conductivity and modifying the associated currents in the E-region, which in turn instantly change and/or affect the Earth's magnetic field on the surface (Davies 1990; Kelley 2009).

In conclusion, magnetic disturbances can be retrieved from geomagnetic data through a comparison between monitoring and remote stations. When typhoons are moving close to monitoring stations, magnetic disturbances with frequency characteristics that concentrate mainly in the 
frequency band between $0.0025-0.007 \mathrm{~Hz}$, are observed. The frequency characteristics are utilized to determine the acoustic waves affecting the geomagnetic field around monitoring stations during the prevailing typhoon period.

Acknowledgements The authors wish to thank the Central Weather Bureau of Taiwan and World Data Center for Geomagnetism at Kyoto University for the retrieval of magnetic data. This research is supported by the Taiwan Earthquake Research Center (TEC) funded through National Science Council (NSC) with grant number NSC 100-2116-M-194012-MY3 and NSC 102-2116-M-001-007. The TEC contribution number for this article is 00100 .

\section{REFERENCES}

Balasis, G. and M. Mandea, 2007: Can electromagnetic disturbances related to the recent great earthquakes be detected by satellite magnetometers? Tectonophysics, $\mathbf{4 3 1}$, 173-195, doi: 10.1016/j.tecto.2006.05.038. [Link]

Chen, C. H., C. R. Lin, H. L. Chao, H. Y. Yen, J. Y. Liu, and Y.H. Yeh, 2009: Evaluation of the applicability of the Chapman-Miller method on variation of the geomagnetic total intensity field in Taiwan from 1988 to 2007. Terr. Atmos. Ocean. Sci., 20, 799-806, doi: 10.3319/ TAO.2009.02.03.01(T). [Link]

Chen, C. H., H. L. Hsu, S. Wen, T. K. Yeh, F. Y. Chang, C. H. Wang, J. Y. Liu, Y. Y. Sun, K. Hattori, H. Y. Yen, and P. Han, 2013: Evaluation of seismo-electric anomalies using magnetic data in Taiwan. Nat. Hazards Earth Syst. Sci., 13, 597-604, doi: 10.5194/nhess13-597-2013. [Link]

Collard, F., F. Ardhuin, and B. Chapron, 2009: Monitoring and analysis of ocean swell fields from space: New methods for routine observations. J. Geophys. Res., 114, C07023, doi: 10.1029/2008JC005215. [Link]

Davies, K., 1990: Ionospheric Radio, IEE Electromagnetic Waves Series 31, The Institution of Engineering and Technology, London, 580 pp.

Francis, S. H., 1973: Acoustic-gravity modes and largescale traveling ionospheric disturbances of a realistic, dissipative atmosphere. J. Geophys. Res., 78, 22782301, doi: 10.1029/JA078i013p02278. [Link]

Fraser, D. C., 1966: The magnetic fields of ocean waves. Geophys. J. Int., 11, 507-517, doi: 10.1111/j.1365246X.1966.tb03162.x. [Link]

Harkrider, D. G., 1964: Theoretical and observed acousticgravity waves from explosive sources in the atmosphere. J. Geophys. Res., 69, 5295-5321, doi: 10.1029/ JZ069i024p05295. [Link]

Iyemori, T., M. Nose, D. Han, Y. Gao, M. Hashizume, N. Choosakul, H. Shinagawa, Y. Tanaka, M. Utsugi, A. Saito, H. McCreadie, Y. Odagi, and F. Yang, 2005:
Geomagnetic pulsations caused by the Sumatra earthquake on December 26, 2004. Geophys. Res. Lett., 32 , L20807, doi: 10.1029/2005GL024083. [Link]

Kelley, M. C., 2009: The Earth's Ionosphere: Plasma Physics and Electrodynamics, $2^{\text {nd }}$ edition, Academic Press, CA., San. Diego, 576 pp.

Kherani, E. A., P. Lognonné, H. Hébert, L. Rolland, E. Astafyeva, G. Occhipinti, P. Coïsson, D. Walwer, and E. R. de Paula, 2012: Modelling of the total electronic content and magnetic field anomalies generated by the 2011 Tohoku-Oki tsunami and associated acousticgravity waves. Geophys. J. Int., 191, 1049-1066, doi: 10.1111/j.1365-246X.2012.05617.x. [Link]

Lilley, F. E. M., J. H. Filloux, P. J. Mulhearn, and I. J. Ferguson, 1993: Magnetic signals from an ocean eddy. $J$. Geomag. Geoelectr., 45, 403-422.

Lilley, F. E. M., A. White, and G. S. Heinson, 2001: Earth's magnetic field: Ocean current contributions to vertical profiles in deep oceans. Geophys. J. Int., 147, 163-175, doi: 10.1046/j.1365-246X.2001.00514.x. [Link]

Lilley, F. E. M., A. P. Hitchman, P. R. Milligan, and T. Pedersen, 2004: Sea-surface observations of the magnetic signals of ocean swells. Geophys. J. Int., 159, 565-572, doi: 10.1111/j.1365-246X.2004.02420.x. [Link]

Liu, J. Y., Y. B. Tsai, S. W. Chen, C. P. Lee, Y. C. Chen, H. Y. Yen, W. Y. Chang, and C. Liu, 2006: Giant ionospheric disturbances excited by the M9.3 Sumatra earthquake of 26 December 2004. Geophys. Res. Lett., 33, L02103, doi: 10.1029/2005GL023963. [Link]

Liu, J. Y., C. H. Chen, C. H. Lin, H. F. Tsai, C. H. Chen, and M. Kamogawa, 2011: Ionospheric disturbances triggered by the 11 March 2011 M9.0 Tohoku earthquake. J. Geophys. Res., 116, A06319, doi: 10.1029/2011JA016761. [Link]

Maus, S. and A. Kuvshinov, 2004: Ocean tidal signals in observatory and satellite magnetic measurements. Geophys. Res. Lett., 31, L15313, doi: 10.1029/2004GL020090. [Link]

Munk, W. H., G. R. Miller, F. E. Snodgrass, and N. F. Barber, 1963: Directional recording of swell from distant storms. Phil. Trans. Roy. Soc. Lond., 255, 505-584, doi: 10.1098/rsta.1963.0011. [Link]

Nishida, K., N. Kobayashi, and Y. Fukao, 2000: Resonant oscillations between the solid earth and the atmosphere. Science, 287, 2244-2246, doi: 10.1126/ science.287.5461.2244. [Link]

Occhipinti, G., P. Lognonné, E. A. Kherani, and H. Hébert, 2006: Three-dimensional waveform modeling of ionospheric signature induced by the 2004 Sumatra tsunami. Geophys. Res. Lett., 33, L20104, doi: 10.1029/2006GL026865. [Link]

Occhipinti, G., E. A. Kherani, and P. Lognonné, 2008: Geomagnetic dependence of ionospheric disturbances 
induced by tsunamigenic internal gravity waves. Geophys. J. Int., 173, 753-765, doi: 10.1111/j.1365-246X.2008.03760.x. [Link]

Occhipinti, G., P. Dorey, T. Farges, and P. Lognonné, 2010: Nostradamus: The radar that wanted to be a seismometer. Geophys. Res. Lett., 37, L18104, doi: 10.1029/2010GL044009. [Link]

Occhipinti, G., P. Coïsson, J. J. Makela, S. Allgeyer, A. Kherani, H. Hébert, and P. Lognonné, 2011: Threedimensional numerical modeling of tsunami-related internal gravity waves in the Hawaiian atmosphere. Earth Planets Space, 63, 847-851, doi: 10.5047/ eps.2011.06.051. [Link]

Occhipinti, G., L. Rolland, P. Lognonné, and S. Watada, 2013: From Sumatra 2004 to Tohoku-Oki 2011: The systematic GPS detection of the ionospheric signature induced by tsunamigenic earthquakes. J. Geophys. Res., 118, 3626-3636, doi: 10.1002/jgra.50322. [Link]

Rolland, L. M., G. Occhipinti, P. Lognonné, and A. Loevenbruck, 2010: Ionospheric gravity waves detected offshore Hawaii after tsunamis. Geophys. Res. Lett., 37, L17101, doi: 10.1029/2010GL044479. [Link]

Rolland, L. M., P. Lognonné, E. Astafyeva, E. A. Kherani, N. Kobayashi, M. Mann, and H. Munekane, 2011:
The resonant response of the ionosphere imaged after the 2011 off the Pacific coast of Tohoku Earthquake. Earth Planets Space, 63, 853-857, doi: 10.5047/ eps.2011.06.020. [Link]

Stopa, J. E., K. F. Cheung, M. A. Garcés, and D. Fee, 2011: Source of microbaroms from tropical cyclone waves. Geophys. Res. Lett., 38, L05602, doi: 10.1029/2010GL046390. [Link]

Tahira,M., 1995: Acoustic resonance of the atmosphere at 3.7 mHz.J.Atmos. Sci., 52, 2670-2674, doi: 10.1175/15200469(1995)052<2670:AROTAA > 2.0.CO;2. [Link]

Weaver, J. T., 1965: Magnetic variations associated with ocean waves and swell. J. Geophys. Res., 70, 19211929, doi: 10.1029/JZ070i008p01921. [Link]

Wen, S., C. H. Chen, H. Y. Yen, T. K. Yeh, J. Y. Liu, K. Hattori, H. Peng, C. H. Wang, and T. C. Shin, 2012: Magnetic storm free ULF analysis in relation with earthquakes in Taiwan. Nat. Hazards Earth Syst. Sci., 12, 1747-1754, doi: 10.5194/nhess-12-1747-2012. [Link]

Yen, H. Y., C. H. Chen, Y. H. Yeh, J. Y. Liu, C. R. Lin, and Y. B. Tsai, 2004: Geomagnetic fluctuations during the 1999 Chi-Chi earthquake in Taiwan. Earth Planets Space, 56, 39-45. 